\title{
Incidence of rough and irregular atmospheric ice particles from Small Ice Detector 3 measurements
}

\author{
Z. Ulanowski ${ }^{1}$, P. H. Kaye ${ }^{1}$, E. Hirst ${ }^{1}$, R. S. Greenaway ${ }^{1}$, R. J. Cotton ${ }^{2}$, E. Hesse ${ }^{1}$, and C. T. Collier ${ }^{1}$ \\ ${ }^{1}$ Centre for Atmospheric and Instrumentation Research, University of Hertfordshire, Hatfield AL10 9AB, UK \\ ${ }^{2}$ Met Office, FitzRoy Road, Exeter EX1 3PB, UK
}

Correspondence to: Z. Ulanowski (z.ulanowski@ herts.ac.uk)

Received: 2 September 2013 - Published in Atmos. Chem. Phys. Discuss.: 25 September 2013

Revised: 17 December 2013 - Accepted: 8 January 2014 - Published: 12 February 2014

\begin{abstract}
The knowledge of properties of ice crystals such as size, shape, concavity and roughness is critical in the context of radiative properties of ice and mixed-phase clouds. Limitations of current cloud probes to measure these properties can be circumvented by acquiring two-dimensional lightscattering patterns instead of particle images. Such patterns were obtained in situ for the first time using the Small Ice Detector 3 (SID-3) probe during several flights in a variety of mid-latitude mixed-phase and cirrus clouds. The patterns are analysed using several measures of pattern texture, selected to reveal the magnitude of particle roughness or complexity. The retrieved roughness is compared to values obtained from a range of well-characterized test particles in the laboratory. It is found that typical in situ roughness corresponds to that found in the rougher subset of the test particles, and sometimes even extends beyond the most extreme values found in the laboratory. In this study we do not differentiate between small-scale, fine surface roughness and large-scale crystal complexity. Instead, we argue that both can have similar manifestations in terms of light-scattering properties and also similar causes. Overall, the in situ data are consistent, with ice particles with highly irregular or rough surfaces being dominant. Similar magnitudes of roughness were found in growth and sublimation zones of cirrus. The roughness was found to be negatively correlated with the halo ratio, but not with other thermodynamic or microphysical properties found in situ. Slightly higher roughness was observed in cirrus forming in clean oceanic air masses than in a continental, polluted one. Overall, the roughness and complexity are expected to lead to increased shortwave cloud reflectivity, in comparison with cirrus composed of more regular, smooth ice crystal shapes. These findings put into question sugges-
\end{abstract}

tions that climate could be modified through aerosol seeding to reduce cirrus cover and optical depth, as the seeding may result in decreased shortwave reflectivity.

\section{Introduction}

Cloud feedbacks remain the largest source of uncertainty in climate models. In particular, uncertainties exist concerning the radiative forcing of clouds containing ice crystals, most notably cirrus. Indeed, whether cirrus clouds warm or cool the Earth surface depends critically on ice crystal morphology, among other factors. Reducing this uncertainty requires detailed in situ characterization of cloud particles, so that the scattering properties of the clouds can be correctly represented in models. Also, detailed knowledge of the scattering properties of various cloud particle types is needed for accurate retrieval of cloud microphysical properties from remote sensing (Baran, 2012; Guignard et al., 2012). One of the main barriers to achieving these goals is the inability of cloud probes to determine the contribution of small ice crystals (that is crystals smaller than about $50 \mu \mathrm{m}$ ) to the total distribution. This is due to crystal breakup on the inlets of these probes (Field et al., 2006) and their inability to resolve precisely the size and shape of small ice crystals because of the conflicting demands of high optical resolution and large sample volume (Ulanowski et al., 2004; Connolly et al., 2007; Kaye et al., 2008; Bailey and Hallett, 2009).

There is also growing evidence, most of it indirect or from remote sensing, that atmospheric ice crystals tend to have shapes departing from idealized geometries based on perfect hexagonal prisms. Typically, aircraft and satellite 
measurements of cirrus radiances show featureless phase functions, which are not consistent with the idealized geometries (Foot, 1988; Baran et al., 2001; Field et al., 2003; Baran, 2004; Garrett, 2008; Baran, 2012). Korolev et al. (2000) concluded that the majority of ice particles in mid-latitude stratiform clouds observed during several campaigns were of irregular shape. Roughness may have been responsible for unexpectedly low values of the asymmetry parameter measured in ice clouds by Garrett et al. (2001). Gayet et al. (2011) found prevalent particles with imperfect or complex shapes at the trailing edge of mid-latitude frontal cirrus, while the leading edge was dominated by more regular plates that produced a $22^{\circ}$ halo signature. For one full day of PARASOL data over ocean, very rough faceted particles provided an improved fit to polarized reflectances (Cole et al., 2013). In a study by Baum et al. (2011) some space-borne depolarization lidar measurements could be explained by modelling ice crystals with rough surfaces. Best fits to data obtained by Lampert et al. (2009) in Arctic ice cloud were consistent with deeply rough hexagonal ice crystals. Measurements using the polar nephelometer indicated that the surface of Antarctic ice crystals was deeply rough (Shcherbakov et al., 2006) . In Arctic mixed-phase clouds Jourdan et al. (2010) found a mix of droplets and deeply rough droxtal-shaped ice crystals; but the droxtal particles were considered as surrogates for small irregular ice crystals.

It is important in this context that particle roughness can dramatically alter the scattering properties of ice crystals. For example, it can significantly reduce the asymmetry parameter (Yang et al., 2008; Ulanowski et al., 2006). Roughness may also account for the relative rarity of ice halos (Yang and Liou, 1998; Mishchenko and Macke, 1999; Ulanowski, 2005). Therefore it is important to quantify fine detail of ice crystal geometry, currently beyond the reach of imaging cloud probes (Ulanowski et al., 2004; Connolly et al., 2007; Bailey and Hallett, 2009), although there are indications that a new generation of probes using incoherent light may be able to resolve at least some of the detail (Schön et al., 2011).

It is possible to circumvent the optical resolution limitations of imaging probes by acquiring light-scattering "patterns" instead of images. Such patterns can be obtained from relatively large sample volumes, as there is no sharply defined image plane to limit resolution. Several light-scattering cloud probes, jointly known as Small Ice Detectors (SID) have been developed over the last decade at the University of Hertfordshire. Successive models obtain scattering patterns with progressively higher angular resolution. The earlier designs rely on multi-element detectors measuring mainly the azimuthal scattering, while the most recent, collectively known as SID-3, acquire high-resolution twodimensional (2-D) scattering patterns (Kaye et al., 2008). Two-dimensional scattering patterns offer high potential for detailed particle characterization. It is possible to recover the shape, size and orientation of small ice particles by comparing such patterns to scattering models such as the Ray
Tracing with Diffraction on Facets (RTDF) model (Clarke et al., 2006; Kaye et al., 2008; Hesse et al., 2009, 2012). Ice particle roughness can also be obtained, as evidenced by experimental patterns from fluorosilicate ice analogue crystals with smooth and rough surfaces, which show distinct differences: while the former have sharp, well-defined bright arcs and spots, the latter have much more random, "speckled" appearance (Ulanowski et al., 2006). The average size of the speckle spots is inversely proportional to particle size, offering a calibration-free method for particle sizing (Ulanowski et al., 2012).

Here we focus on the application of 2-D scattering patterns to retrieving the roughness of atmospheric ice particles. We use the first airborne data from the SID-3 probe, obtained in mid-latitude cirrus and mixed-phase clouds during the UK Met Office CONSTRAIN campaign in 2010. Several features of the patterns are used to assess the roughness of the corresponding ice particles. The features are compared to those obtained from natural and artificial particles of varying surface roughness and complexity. We then examine possible causes of the observed roughness. In addition to growth processes we also consider sublimation, since ice surfaces can become rough during rapid sublimation (Cross, 1969; Kobayashi and Ohtake, 1974; Pfalzgraff et al., 2010). This is contrary to what currently appears to be the prevailing view, which postulates that atmospheric ice crystals merely become rounded (Nelson, 1998). We investigate this dilemma by examining in situ cloud data as well as laboratory cases of crystal sublimation and dissolution.

Due to limitations of in situ cloud probes, little is known about the detail of surface structure of atmospheric ice crystals, although some attempts have been made to quantify it in the laboratory (Neshyba et al., 2013), and it has been postulated that it may be anisotropic in nature (Shcherbakov, 2013). Speckle techniques for the quantitative measurement of roughness depend on assumptions about the vertical surface height distribution (roughness amplitude or variance) and autocovariance function (horizontal correlation length). Moreover, particle surface roughness, as represented by parameters such as the amplitude of variance of surface height, is not in general related in a simple, linear manner to speckle properties, except for low roughness, smaller than the wavelength of light (Goodman, 2007). For these reasons, fully quantitative measurement of roughness cannot yet be obtained with the available data. Consequently, in this work we focus on semi-quantitative, exploratory analysis and comparisons between data from atmospheric ice and test particles with known geometry. Furthermore, whilst the average area of speckle spots is known to be inversely proportional to the size of the scattering particle, the width of the intensity "envelope" of the speckle pattern is expected to be related to the transverse scale of surface roughness (Ulanowski et al., 2012). This may in the future allow the recovery of such scale from speckle patterns, but further research is needed in this area. In the meantime, we limit ourselves to treating 


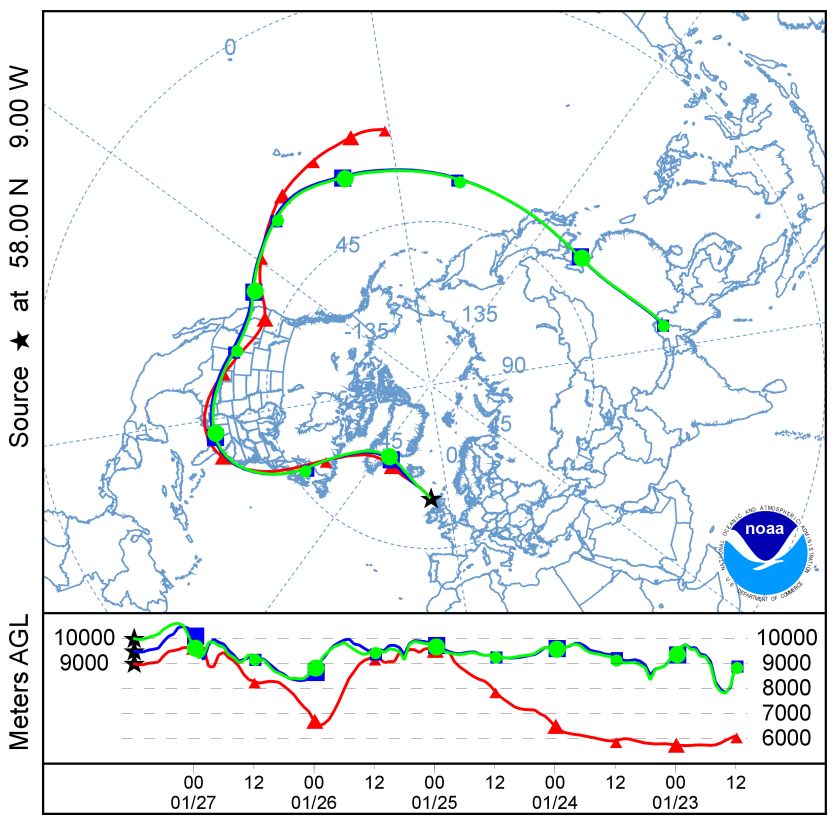

Fig. 1. 5-day backward air mass trajectories for cirrus flight B504 ending at 12:00 UTC on 27 January 2010, computed for final altitudes of 9000,9500 and $10000 \mathrm{~m}$. The lower panel shows the altitude above ground level in metres.

in the same way particles that may be characterized by different transverse scales of roughness. This may include fine, wavelength-scale roughness at one extreme, and large-scale complexity at the other extreme.

\section{Methods}

The first in situ cloud data from the SID-3 probe were obtained during the UK Met Office CONSTRAIN campaign in Scotland in January and February 2010, with another case, flight B558, in south-eastern England in September 2010. Three flights in this analysis - B503 (25 January), B504 (27 January) and B558 (28 September) - sampled cirrus, and two, B505 (29 January) and B509 (16 February) mixedphase clouds. The cloud sampled was mostly mid-latitude stratiform cirrus associated with fronts within cyclonic systems. The aircraft sampling pattern consisted of a series of level runs each separated in altitude by $1000 \mathrm{ft}$, and ranged from near cloud top to below cloud base. The cirrus cloud top temperatures were around $-60^{\circ} \mathrm{C}$ and the cloud base around $-30^{\circ} \mathrm{C}$. Observations near the cloud base included sublimating particles. The relative humidity with respect to ice, using the General Eastern chilled mirror hygrometer was mostly between 80 and $110 \%$ throughout the depth of the cloud. The highest altitude reached during these flights was $10.9 \mathrm{~km}$. Flight B509 was also in a frontal origin cloud, but its base was much lower $(\approx 1 \mathrm{~km})$ so it was mixed phase; it was profiled up to cloud top near $4.5 \mathrm{~km}$. Flight B505 was in

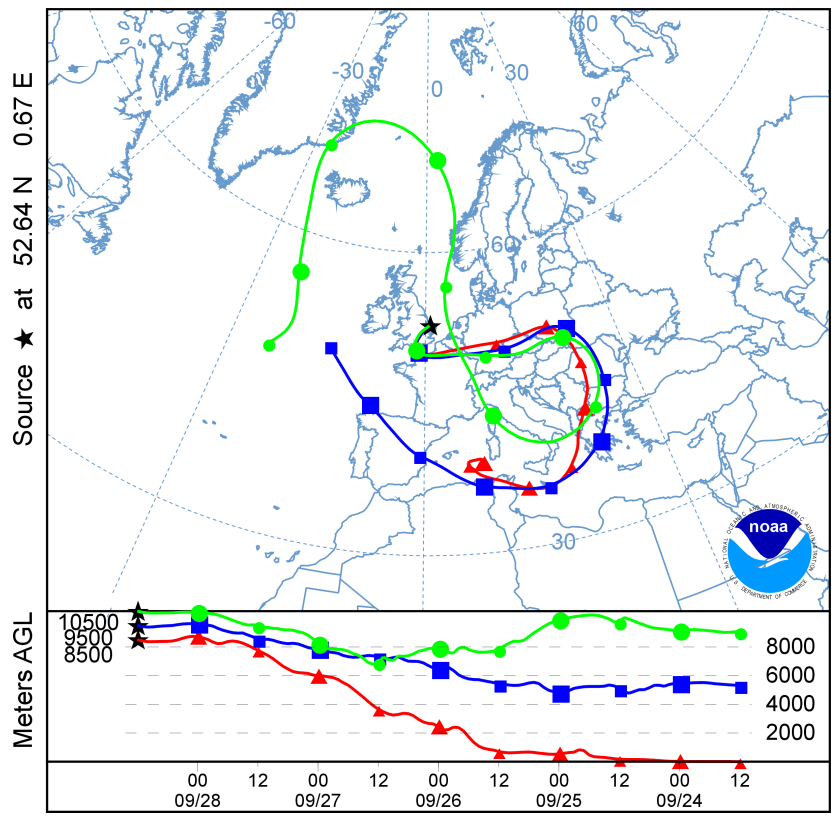

Fig. 2. As Fig. 1 but for cirrus flight B558 ending at 12:00 UTC on 28 September 2010, computed for final altitudes of 8500,9500 and $10500 \mathrm{~m}$.

a congested, supercooled cumulus; it was profiled up to cloud top near $3 \mathrm{~km}$. Most of the flights were in prevailing oceanic air mass, with the exception of B558. Air mass origin was determined using trajectory analysis. Five-day back trajectories were computed using the NOAA HYSPLIT model with GDAS meteorological data, using vertical model velocities (Draxler and Rolph, 2003). The trajectories for flights B504 (oceanic air mass) and B558 (continental air mass) are shown in Figs. 1 and 2, respectively.

SID-3 was flown in a PMS-style canister on the FAAM research aircraft. The probe has "open" geometry similar to SID-2 - Fig. 3. This design minimizes the incidence of ice particles shattered on the probe housing (Cotton et al., 2010, 2013). Specifically, during CONSTRAIN shattering was not thought to be important for SID-2 (Cotton et al., 2013). Since SID-3 has very similar geometry, it is unlikely that shattering could have influenced the measurements significantly. Particle triggering (two photomultipliers defining the sample volume), incident illumination (532 nm wavelength laser beam) and sample volume definition are also similar to SID-2 (Cotton et al., 2010). However, the main detector of SID-3 is an intensified CCD camera (Photek Ltd, UK) producing images 780 by 582 pixels in size. The gain of the intensifier, and hence the resulting image brightness, can be varied under software control. The camera delivers 2-D scattering patterns from single particles at rates up to 30 per second, depending on configuration. Since the sampling volume for the airborne instrument is typically about $50 \mathrm{~mL} \mathrm{~s}^{-1}$ in flight, not all particles can be captured as 2-D patterns at higher concentrations. However, data from the trigger channels are recorded, 


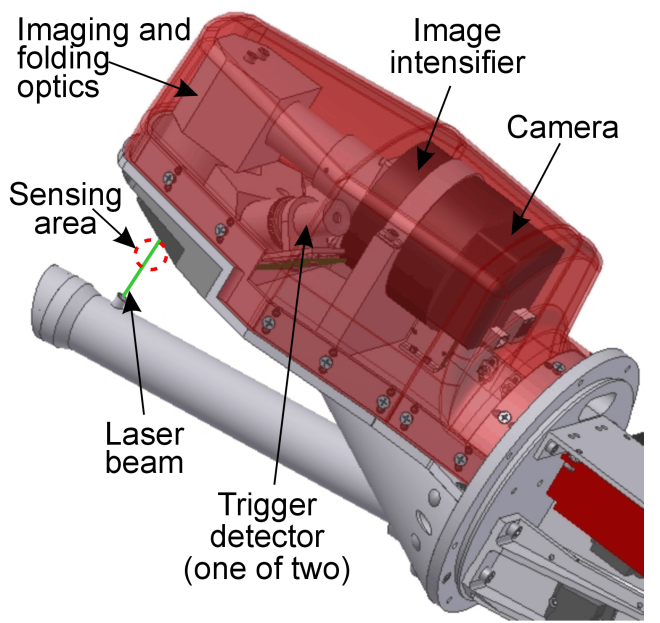

Fig. 3. Schematic view of the head of the SID-3 instrument. Only a small part of the instrument inside the PMS canister is visible (lower right). The sensing area shown is positioned $17.4 \mathrm{~mm}$ from the faceplate of the instrument.

including amplitude histograms, allowing some reconstruction of particle number concentrations. Receiving optics collect the scattered light over an annulus covering scattering angles from 6 to $25^{\circ}$, sufficient to encompass the $22^{\circ}$ halo scattering from ice prisms, but with the central low-angle area obscured by a beam stop. Several instruments based on this principle have been constructed, including both airborne and laboratory versions (Kaye et al., 2008). The camera images of the 2-D patterns were digitized in this study as 8-bit compressed JPEG files, although the system is also capable of producing lossless 12-bit TIFF files. Since the 8-bit brightness is quite narrow in terms of dynamic range, and the intention was to collect images from small as well as larger ice particles, the intensifier gain was switched every three seconds between two values differing typically by a factor of 10.

In addition to in situ data, SID-3 2-D patterns were also obtained from a variety of single test particles in the laboratory. For these measurements, rough and smooth mineral dust grains (Ulanowski et al., 2012) and ice analogue crystals (refractive index of 1.31) with smooth surfaces, rough surfaces or complex structure were used (Ulanowski et al., 2003, 2006). They were deposited on anti-reflection coated glass windows with specified reflectance $<0.2 \%$ per surface. Test particle size was obtained from optical microscopy images taken in the same particle orientation as in the scattering data. Most of these particles were also visualized using scanning electron microscopy (SEM). Details of the particles are given in Table 3. SEM images of most of the test particles were taken using a JEOL-5700 environmental SEM, and of dissolved ice analogues using a Camscan CS44 SEM. All SEM images were obtained with backscattered electron detectors under low vacuum and without specimen coating.
Images of ice crystals were obtained in the presence of water vapour in the SEM chamber (pressure $\approx 40 \mathrm{~Pa}$ ) with only residual amounts of air. Ice was grown from water vapour on a metal substrate on a Deben Ultra Peltier-cooled cold stage, and sublimated by increasing the substrate temperature.

Image texture can be quantified using statistical measures, e.g. the grey-level co-occurrence matrix (GLCM), which deals with spatial relationships of pairs of grey-value pixels (Haralick et al., 1973). Previously, GLCM was applied to retrieving surface roughness from laser speckle images ( $\mathrm{Lu}$ et al., 2006). Initially, four GLCM features were chosen: contrast, correlation, energy and homogeneity. They were calculated for nearest neighbour pixels in four directions (Haralick et al., 1973). In addition, image entropy and two measures relating to image brightness distribution, rather than texture, were examined: the ratio of root-mean-square brightness (RMS) to its standard deviation (SD) (RMS / SD; Jolic et al., 1994), and kurtosis (defined as fourth moment about the mean divided by the 4th power of the standard deviation). We emphasize that, while the GLCM depends on spatial structure of the image (relative brightness of neighbouring pixels), RMS / SD and kurtosis do not (they describe only the statistical distribution of brightness over the entirety of the image), so they express somewhat different properties of speckle. To calculate the measures, only the pixels from SID-3 image within the 6 to $25^{\circ}$ scattering angle range were used, i.e. only within the image annulus. The measures were calculated for SID-3 2-D patterns obtained from a range of test particles: smooth and rough ice analogues and mineral dust grains, and correlated with a semi-quantitative measure of particle roughness. We also examined the sensitivity of the same measures to potential bias sources, including image noise, saturation, particle size, shape and orientation, and image intensifier gain (hence image brightness). Various image normalization and averaging schemes were compared too, and the chosen one involved scaling mean image brightness to 10 on the $0-255$ scale.

Of the four GLCM features, energy was found to have the strongest correlation with particle roughness and was most robust with respect to the potential bias sources. It is relevant that the GLCM energy also shows good correlation with roughness in the context of laser speckle from flat surfaces, and is most robust with respect to variation of "the setup configuration, the position, and the orientation of the surface to be measured" (Lu et al., 2006). So only this GLCM feature is reported henceforth. Similar performance characterized the remaining measures: entropy, RMS / SD and kurtosis; but different measures showed sensitivity to different sources of bias. For example, entropy was more sensitive to gain, particle size and noise in the images, so it was not included in further analysis. Kurtosis on the other hand was sensitive to detector gain (image brightness). A "combined roughness" measure was also defined, composed of the most robust measures, energy $E$, RMS / SD and the base 10 logarithm of 


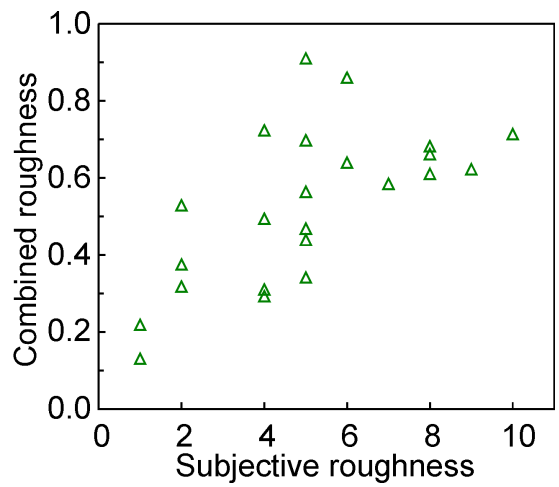

Fig. 4. Combined roughness measure of test particles plotted against subjective roughness (see Sect. 2). A wider range of particles than in Table 3 was tested.

kurtosis $K$, as follows:

$$
0.7-2 E / 3-(\log K) / 6+(\mathrm{RMS} / \mathrm{SD}) / 4000 \text {. }
$$

The signs in front of the individual terms reflect the signs of the correlations with roughness: negative for energy and kurtosis and positive for RMS / SD.

The combined roughness measure was weighted so that the individual measures contributed to it approximately equally and it had bounds of 0 and 1 for most particles encountered (although these bounds can be exceeded for very smooth or very rough particles). The combined roughness was characterized by reduced sensitivity to image brightness, although it still showed sensitivity to image saturation. To reduce the impact of the residual bias sensitivities, very dark or excessively saturated patterns were removed from further analysis: minimum brightness was set at 4 and maximum number of saturated pixels at 1000 (excluding the central beam stop).

The selected image features were calculated for 2-D patterns from cirrus and mixed-phase cloud particles as well as test particles including mineral dust grains and smooth and rough ice analogues. The measures obtained from the test particles were correlated with a subjective measure of particle roughness derived from microscopy images - Fig. 4 shows the correlation with the combined roughness. We also attempted to retrieve surface profiles of the test particles from stereo images taken using SEM, but these proved to be inaccurate, especially for the somewhat heterogeneous mineral dust grains, unless destructive specimen preparation procedures were used, so this route was abandoned in order to maintain intact test particle collection for further work. Ice particle size was retrieved from the SID-3 patterns by determining average speckle area, which is inversely proportional to particle size, using a method described previously (Ulanowski et al., 2012).

Relative humidity with respect to ice was determined from water vapour concentration measured on FAAM using the Fluorescent Water Vapor Sensor (FWVS) fast Lyman-alpha

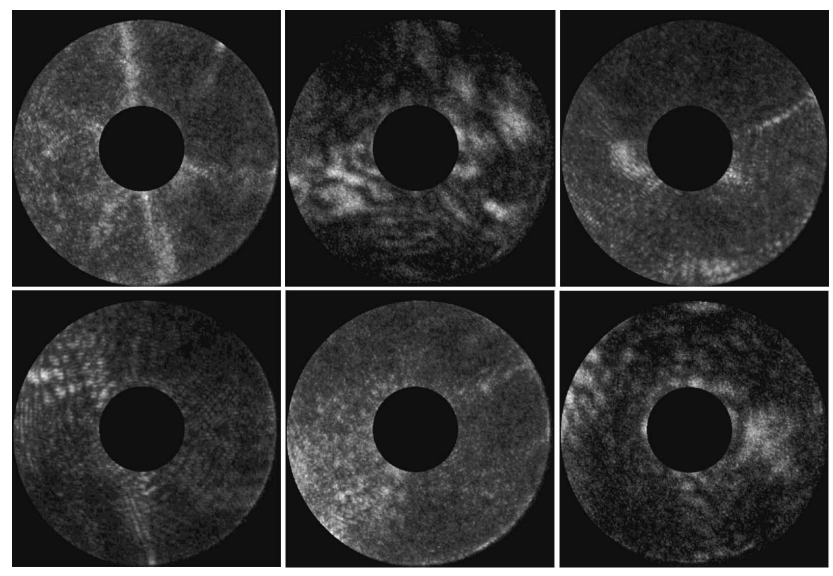

Fig. 5. Six randomly selected SID-3 patterns from ice particles seen during CONSTRAIN cirrus (top) and mixed-phase (bottom) flights.

hygrometer, built and maintained by the UK Met Office (Keramitsoglou et al., 2002; Fahey et al., 2009).

The so-called "halo ratio" (HR) is a quantitative criterion to characterize the occurrence of the $22^{\circ}$ halo peak. It is defined by the ratio of the scattered energy values measured at the scattering angles of $22^{\circ}$ and $18.5^{\circ}$. As such, it is sensitive to the presence in ice crystals of the $60^{\circ}$ prism angle and to the smoothness of the prismatic faces (Auriol et al., 2001; Gayet et al., 2011). Here it was calculated by averaging SID-3 image brightness between the scattering angles from $21.5^{\circ}$ to $22.5^{\circ}$, and from $18^{\circ}$ to $19^{\circ}$, and taking the ratio of the respective averages. To aid azimuthal averaging, the images were first converted from Cartesian to polar coordinates, using triangle-based linear interpolation.

\section{Results}

Figure 5 shows a typical selection of SID-3 scattering patterns from ice particles from the CONSTRAIN flight campaign. The roughness measures were calculated for a random selection of several hundred patterns from marine cirrus (239 patterns) and mixed-phase (199 patterns) flights, as well as one cirrus flight in a continental air mass (59 patterns). The roughness measures are summarized in Table 1 and the frequency distributions are shown in Fig. 6. Statistical significance tests for differences between the roughness measures were carried out using the $t$ test method, assuming unequal variances. The probabilities that the null hypothesis of no difference between the measures is true are given in Table 2.

The roughness measures were also calculated for a range of test particles, including ice analogue crystals (Ulanowski et al., 2006) and mineral dust grains, all representing a range of surface roughness - the results are given in Table 3, and the magnitudes and range of the roughness measure values of the test particles are shown graphically above the frequency distributions in Fig. 6. Images of the test particles from Table 3, 
Table 1. Mean values and standard deviations (in brackets) of roughness measures of ice crystals in the three cloud cases shown in Fig. 6 , obtained from 2-D SID-3 scattering patterns.

\begin{tabular}{lrrrr}
\hline Case & Energy & $\log K$ & RMS /SD & Combined roughness \\
\hline Marine cirrus & $0.239(0.084)$ & $1.38(0.39)$ & $1100(336)$ & $0.586(0.175)$ \\
Continental & $0.218(0.062)$ & $1.33(0.25)$ & $605(139)$ & $0.485(0.103)$ \\
Mixed phase & $0.224(0.0714)$ & $1.20(0.26)$ & $936(228)$ & $0.586(0.123)$ \\
\hline
\end{tabular}
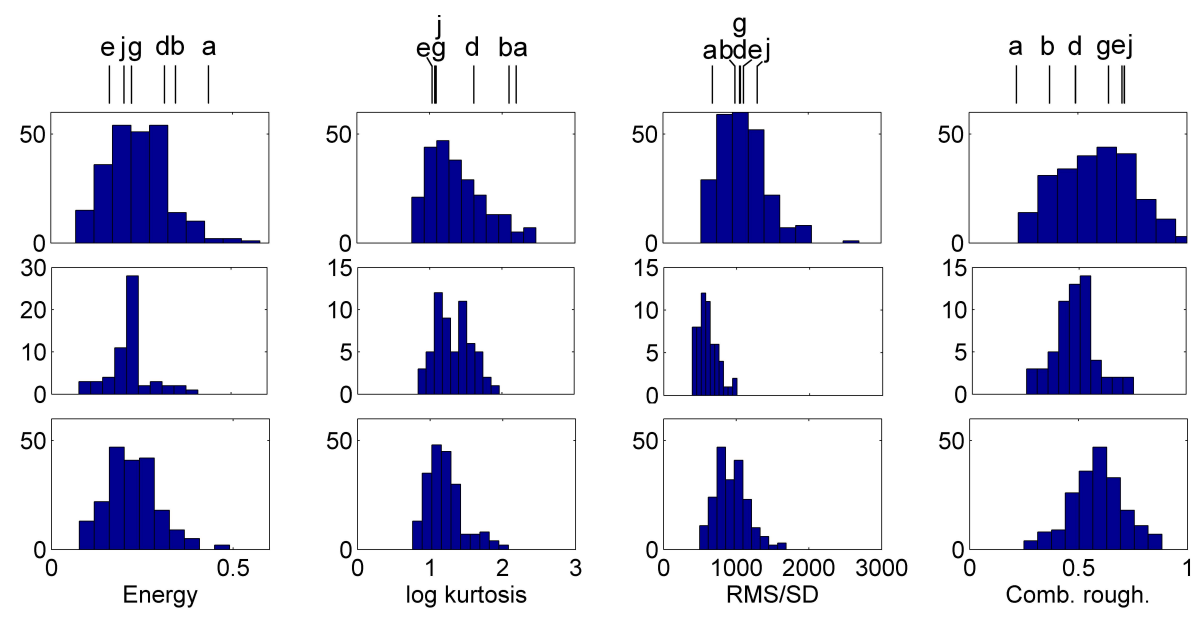

Fig. 6. Frequency distributions of roughness measures obtained from SID-3 2-D patterns in marine air mass cirrus (top row), continental air mass cirrus (middle row), and mixed-phase clouds (bottom row) flights. Labelled lines above the distributions show roughness measure values for six test particles from Table 3 and Fig. 7: (a), (b), (d), (e), (g) and (j), where (a) is the smoothest and (j) the roughest one. Note that the GLCM energy and log kurtosis are anticorrelated with roughness.

together with corresponding SID-3 scattering patterns, are shown in Fig. 7. A total of 23 test patterns from 16 particles were used in the comparison given here, as shown in Fig. 4. Data from some of the particles were obtained for two orientations and up to three different image intensifier gain values. For example, for particle (b) and (f) there were two gains and two orientations, for particle (e) two orientations, and for particle (f) three gains and two orientations. The variability of roughness measures can be seen in Fig. 4 by looking at the spread of data points along the vertical axis. Different orientations were included because we had found that the speckle measures varied with particle orientation. For example, for the particles (b), (e) and (f) the combined roughness varied with orientation between 0.32 and $0.38,0.34$ and 0.7 , and 0.78 and 0.87 , respectively. We interpret this variability as originating partly or mostly from the fact that the roughness measures depend on the presence or absence of features in the 2-D scattering patterns: for smooth crystals bright spots and arcs appear (Ulanowski et al., 2006), and their presence leads to lowered roughness measures. However, the position of these features depends on crystal orientation, and in some orientations they may disappear entirely from the 6 to $25^{\circ}$ scattering angle range encompassed by the SID-3 detector. For instance, the existence of the $22^{\circ}$ halo peak is equivalent to the presence of bright spots in the 2-D pattern at scattering angles $>22^{\circ}$.

The roughness measures were examined for possible correlation with other variables measured during the flights, including temperature, ice supersaturation, vertical velocity, ice particle size, ice particle number concentration and large aerosol concentration, although not all of these variables were available simultaneously for all flights. Generally, the correlations were weak - an example is given in Fig. 8, which shows roughness plotted against relative humidity with respect to ice. In contrast, stronger negative correlation was found between roughness and the halo ratio determined from the SID-3 patterns - see Fig. 9. The least-squares regression between the halo ratio (HR) and RMS / SD was HR = $1.11-0.125 \times 10^{-3} \mathrm{RMS} / \mathrm{SD}$.

We also carried out initial investigations of possible processes that may lead to the formation of rough ice surfaces, using ice as well as ice analogues as materials. a scanning electron microscopy image of ice crystals grown and then partially sublimated in the presence of water vapour in the microscope chamber is shown in Fig. 10. It is noticeable that surfaces deeper within the sample remained smooth, while the exposed ones become roughened, and that the prismatic facets showed grooves perpendicular to the crystal $c$ axis, while the roughness on the basal facets was isotropic. 


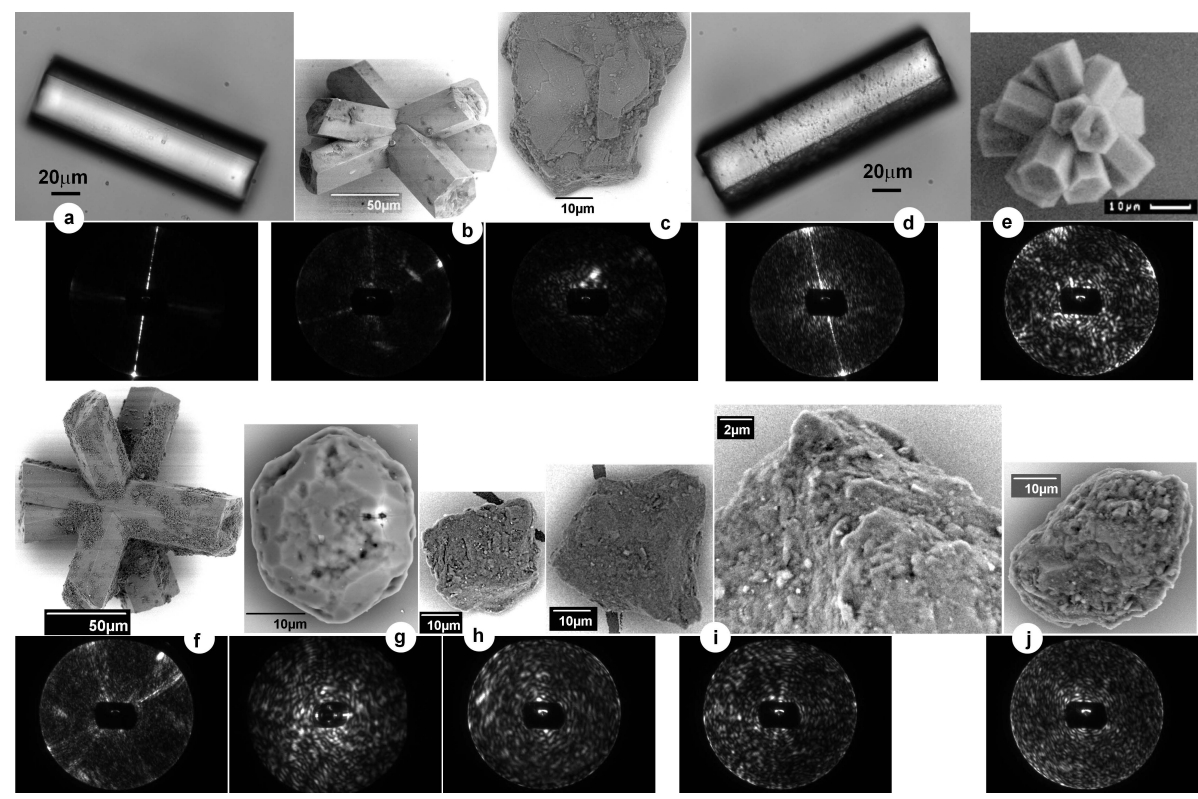

Fig. 7. Upper rows: images of test particles from optical microscopy (ice analogue columns (a) and (d) only) or SEM, labelled with the ID letters from Table 3, with size scales shown in insets - note that the magnifications vary; the dust grain (i) is shown in two magnifications. Lower rows: corresponding SID-3 scattering patterns.

Table 2. Significance tests for differences between the roughness measures of ice crystals in the three cloud cases shown in Fig. 6 (marine cirrus, continental cirrus, mixed phase), obtained using the $t$ test method. Shown are the probabilities that the null hypothesis of no difference between the measures is true (low probabilities correspond to more significant differences). Values $<5 \%$ are given in bold to highlight significant differences.

\begin{tabular}{llcccc}
\hline Case A & Case B & $\begin{array}{c}\text { Energy } \\
(\%)\end{array}$ & $\begin{array}{c}\log K \\
(\%)\end{array}$ & $\begin{array}{c}\text { RMS } / \text { SD } \\
(\%)\end{array}$ & $\begin{array}{c}\text { Combined roughness } \\
(\%)\end{array}$ \\
\hline Marine & Continental & $\mathbf{3 . 9}$ & 18 & $\mathbf{4 . 3} \times \mathbf{1 0}^{-\mathbf{4 2}}$ & $\mathbf{5 . 0} \times \mathbf{1 0}^{-\mathbf{6}}$ \\
Marine & Mixed phase & $\mathbf{4 . 2}$ & $\mathbf{4 . 7} \times \mathbf{1 0}^{-\mathbf{7}}$ & $\mathbf{3 . 0} \times \mathbf{1 0}^{-\mathbf{7}}$ & 99 \\
Continental & Mixed phase & 59 & $\mathbf{6 . 3} \times \mathbf{1 0}^{-\mathbf{2}}$ & $\mathbf{1 . 4} \times \mathbf{1 0}^{-\mathbf{3 7}}$ & $\mathbf{6 . 5} \times \mathbf{1 0}^{-\mathbf{7}}$ \\
\hline
\end{tabular}

Overall, we found that, while irregular growth could be produced under high supersaturation, in general fine roughness was easier to obtain by sublimation than by growth. Typical SEM images of ice analogues grown from solution under low and high supersaturation are represented by the test particles "a" or "b", and "g", respectively, in Fig. 7. The former pair shows regular hexagonal shapes with smooth, flat facets, while the latter crystal is highly deformed. Regular ice analogue crystals were partially dissolved by immersing them in subsaturated sodium fluorosilicate solution, while observing them continuously using optical microscopy. A typical example is shown in Fig. 11: following dissolution at $99 \%$ saturation the crystal could be seen to attain oval outline, with only a hint of underlying fine structure. However, the higherresolution SEM image of another crystal from the same batch shown in Fig. 12 reveals much fine detail, including pronounced ridges and cavities. It must be noted that the numerical aperture of the optical microscope (0.4), and hence the resolution, was higher than for imaging cloud probes, so the latter would reveal even less detail.

\section{Discussion}

We have presented here the first, exploratory results from in situ measurements using the SID-3 cloud probe, which allows ice particle characterization through the analysis of 2-D scattering patterns, instead of images. We have found that the scattering patterns obtained in both cirrus and mixed-phase clouds during the CONSTRAIN campaign in 2010 were typically characterized by the presence of pronounced speckle. Qualitatively, these patterns are similar in appearance to patterns obtained from the rougher particles in the test particle selection shown in Fig. 7. Comparison of the distributions of in situ roughness measures shown in Fig. 6 with roughness values for the test particles reveals that smoother particles corresponded to the tails of the roughness distributions. The 
Table 3. Ice analogue and mineral dust test particles in increasing order of subjective roughness (see Sect. 2). The size is the approximate maximum dimension. The roughness measures are GLCM energy $E, \log$ kurtosis $\log K$, RMS / SD and "combined roughness" (see text); the signs in brackets indicate the sign of correlation with roughness.

\begin{tabular}{llrrrrrr}
\hline ID & Type & $\begin{array}{r}\text { Size } \\
(\mu \mathrm{m})\end{array}$ & $\begin{array}{r}E \\
(-)\end{array}$ & $\begin{array}{r}\log K \\
(-)\end{array}$ & $\begin{array}{r}\text { RMS / SD } \\
(+)\end{array}$ & $\begin{array}{r}\text { Combined } \\
(+)\end{array}$ & $\begin{array}{r}\text { Subjective } \\
\text { roughness }\end{array}$ \\
\hline $\mathrm{a}$ & Analogue column & 140 & 0.43 & 2.18 & 683 & 0.22 & 1 \\
$\mathrm{~b}$ & Analogue rosette & 150 & 0.34 & 2.08 & 993 & 0.37 & 2 \\
$\mathrm{c}$ & Dust, smooth & 65 & 0.32 & 2.15 & 733 & 0.31 & 4 \\
$\mathrm{~d}$ & Analogue column & 160 & 0.31 & 1.60 & 1059 & 0.49 & 4 \\
$\mathrm{e}$ & Analogue rosette & 51 & 0.16 & 1.03 & 1107 & 0.70 & 5 \\
$\mathrm{f}$ & Analogue rosette & 160 & 0.29 & 1.42 & 1171 & 0.56 & 5 \\
$\mathrm{~g}$ & Analogue plate & 30 & 0.22 & 1.08 & 1052 & 0.64 & 6 \\
$\mathrm{~h}$ & Dust, rough & 35 & 0.23 & 1.26 & 1294 & 0.68 & 8 \\
$\mathrm{i}$ & Dust, rough & 47 & 0.24 & 1.12 & 1088 & 0.62 & 9 \\
$\mathrm{j}$ & Dust, rough & 46 & 0.20 & 1.07 & 1298 & 0.71 & 10 \\
\hline
\end{tabular}

distributions were better represented by the rougher or more irregular particles in the selection, such as the highly distorted ice analogue prisms ( $\mathrm{d}$ and $\mathrm{g}$ ), the "germ" or rough ice analogue rosettes (e and f) or the rough mineral dust grains (h, i and j). The "rough" tails of the roughness measure distributions extended in some cases beyond the roughness values obtained for the roughest particles tested.

Phase functions of smooth and rough ice analogue rosettes very similar to those used here was previously measured using a levitation technique. It was found that the transition from smooth to rough geometry for these large $(\approx 90 \mu \mathrm{m}$ maximum dimension) crystals lowered the asymmetry parameter from 0.81 to about 0.63 (Ulanowski et al., 2006). It is worth noting that such a large change corresponds to almost doubling the reflectivity of a cloud composed entirely of such particles. Similar lowering of the asymmetry parameter between smooth and rough particles was found for mineral dust grains (McCall, 2011).

The halo ratio calculated from scattering phase functions is a measure of the quality of the $22^{\circ}$ halo peak and as such indicates ice particle "regularity". The halo ratio and asymmetry parameter measured in situ are positively correlated (Auriol et al., 2001; Gayet et al., 2011). The halo ratios of the sets of smooth and rough ice analogue crystals measured previously (Ulanowski et al., 2006) were 1.40 and 0.89 , respectively. We also found negative correlation between roughness and the halo ratio determined in cirrus (Fig. 9). The correlation is statistically highly significant. Moreover, the halo ratio was determined for single particles, each in its own orientation; as such, the ratio is subject to very wide variation due to the orientation, which is likely to cause most of the observed variability. Had the halo ratio been determined for an ensemble of particles (as is the case for the polar nephelometer), the variability is likely to have been much lower. The presence of the correlation reinforces the expectation that negative correlation should be present between the retrieved roughness and the asymmetry parameter of the in situ ice par- ticles. The 2-D patterns obtained for test particles show that substantial speckle can result either from small-scale, fine roughness or from complexity - the former example being mineral dust grains, the latter the complex, "germ rosette" with smooth prismatic facets. This similarity is not surprising, as speckle will arise if multiple "scattering centres" mutually incoherent radiating regions - are present on the surface of the particle (Goodman, 2007; Ulanowski et al., 2012). This can occur if particle surfaces are rough, or the geometry of the particle is very complex, so that scattering in any given direction contains contributions from different particle regions, leading to interference. The same should apply to hollow crystals, as additional facets would be present. Moreover, for speckle to occur, the wavefront delays (phase differences) introduced into the scattered wave by these regions must be comparable to or greater than the wavelength of light; but what matters is the difference between the delay and the whole number of wavelengths, rather than the absolute delays (the phase is "wrapped" modulo $2 \pi$ ). Therefore, both small and large departures from surface flatness can influence scattering in similar ways. a corollary of the presence of such phase-delaying centres in the case of ice crystals is that parallel facets are no longer present. Parallel facets give rise to unscattered "delta rays" ( $\delta$-function transmission) in the large particle (geometric optics) limit (Takano and Liou, 1989; Mishchenko and Macke, 1998) or forwardscattered light in general (once diffraction has been properly accounted for). So the absence of parallel facets leads to increased scattering at larger angles and, in turn, lower asymmetry parameter, due to its cosine weighting factor (Nousiainen et al., 2011).

Thus overall, roughness and complexity appear to impact not just 2-D scattering but other scattering properties in a similar manner. The reduction in the asymmetry parameter is shown by both measurement and modelling studies (Ulanowski et al., 2006; Yang et al., 2008; Um and McFarquhar, 2011). In a manner, whatever the 


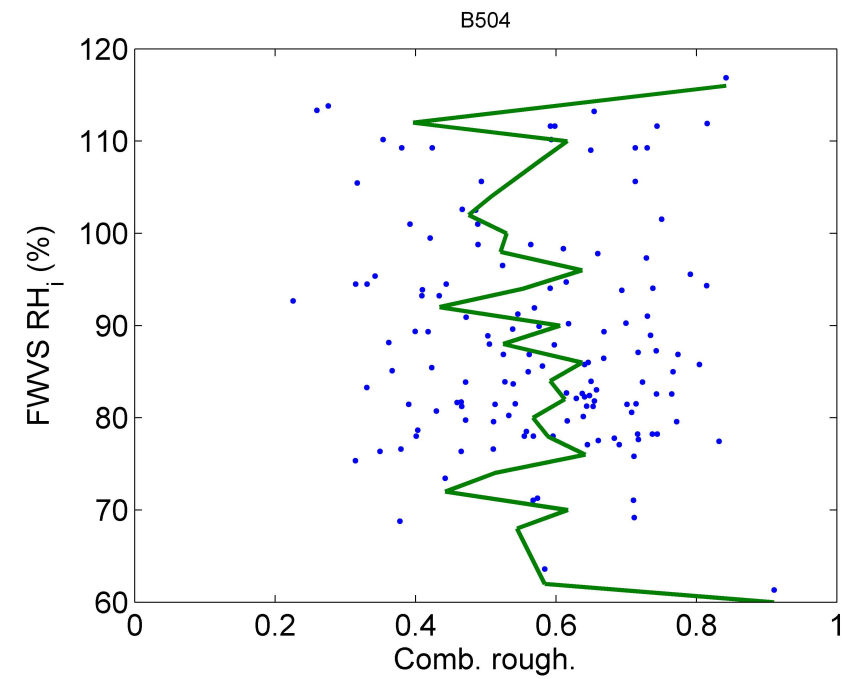

Fig. 8. Relative humidity with respect to ice measured using the FWVS hygrometer on the FAAM aircraft during the cirrus flight B504, plotted against ice particle roughness as represented by the "combined roughness" measure (points) and mean roughness (line). Average temperature during the relevant flight sections was $-54{ }^{\circ} \mathrm{C}$.

"roughness" structure, large rough particles acquire some scattering properties that are more characteristic of small particles, i.e. strong side-scattering and low asymmetry parameter (Ulanowski et al., 2006; Um and McFarquhar, 2011).

Concerning the mineral dust grains as surrogates for ice particles, while the refractive index of mineral dust is higher, the difference in roughness that would be caused by such change is small: if dust is substituted for ice, the same speckle pattern should be obtained if dust roughness is $1.31 / n_{\mathrm{m}}$ of that of ice (Ruiz Gale et al., 2007), where $n_{\mathrm{m}}$, the refractive index of mineral dust, is typically $\approx 1.52$. So the dust particles may represent both the scattering properties and possibly also the shape of atmospheric ice crystal quite well, at least as far as solid (as opposed to hollow), simple (as opposed to branched or aggregated) crystals are concerned. But we must keep in mind the caveats concerning the possible ambiguity between rough and complex particles. At the same time we note that the roughness magnitudes found in situ exceeded those found for the roughest test particles we could procure; this suggests that both large-scale complexity and high small-scale surface roughness may have been present in at least some ice particles. An example of such a particle might be a rosette or aggregate with very rough surfaces the type of particle not present in our test collection.

Imaging cloud particle probes have difficulty resolving not only fine surface roughness but also larger detail of complex particles. Complex near-spherical crystals, which could potentially take on a variety of possible shapes - such as, for example, germ rosettes ("budding Bucky balls") - are typically classified simply as "irregulars", and in the past were even categorized as spheres. However, spheres or even compact,

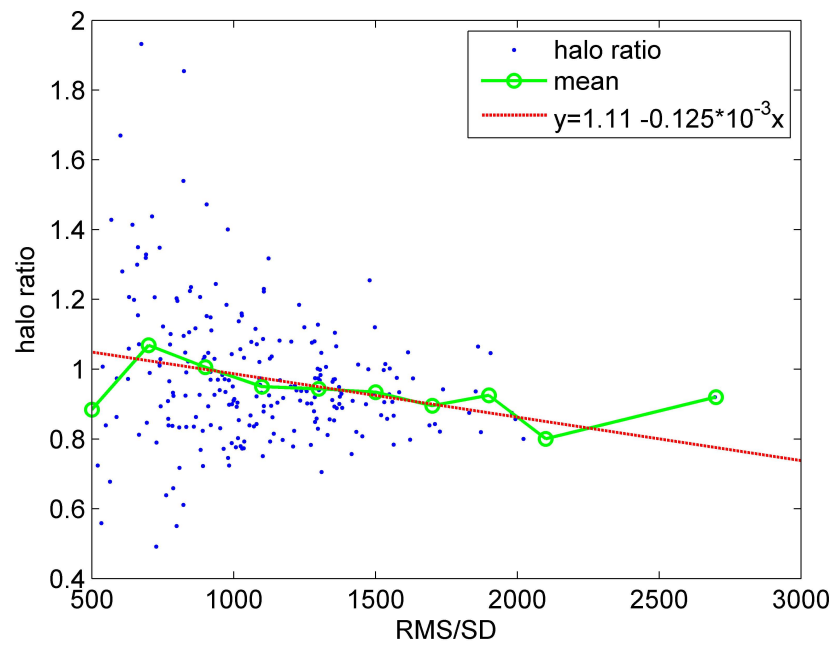

Fig. 9. Halo ratio plotted against particle roughness measure RMD/SD, both determined from SID-3 patterns obtained in cirrus formed in marine air masses. Mean halo ratio calculated for fixed roughness intervals, and a least-squares regression line (coefficients given in the legend) are also shown. The correlation coefficient was -0.22 , significant at the $0.1 \%$ level, based on 239 data points.

non-spherical shapes like ellipsoids generally have dramatically different scattering properties from complex, facetted particles, including larger asymmetry parameter (Ulanowski et al., 2004; Connolly et al., 2007; Um and McFarquhar, 2011). Thus it is very important to correctly identify such particles from in situ data and to represent their scattering properties appropriately in models. Speckle analysis offers the first step in this process, and while discrimination from particles with fine roughness is not yet carried out, it may not be essential due to the similarity of the scattering properties. Moreover, as the above discussion illustrates, smallscale roughness and large-scale complexity can have similar causes, for example the presence of high water vapour supersaturation with respect to ice, lessening further the need for detailed categorization.

Possible causes of the prevalent ice crystal roughness may be related to details of the ice crystal growth process, the level of water vapour supersaturation, ice sublimation, and also the type of nucleation. Homogeneously frozen ice can contain high concentration of stacking faults, leading to partly ordered crystalline structure, neither hexagonal nor cubic. Such structure can be expected to lead to poorly defined facet geometry and the emergence of rough surfaces (Malkin et al., 2012).

Nelson (1998) suggests that repeated cycles of supersaturation and undersaturation are likely to lead to more complex, "exaggerated" crystal shapes, as a consequence of asymmetry between growth and sublimation. Therefore mixing and small-scale vertical motions in clouds, leading to the presence of many growth and sublimation regions, may be a possible mechanism by which roughness emerges (Korolev 


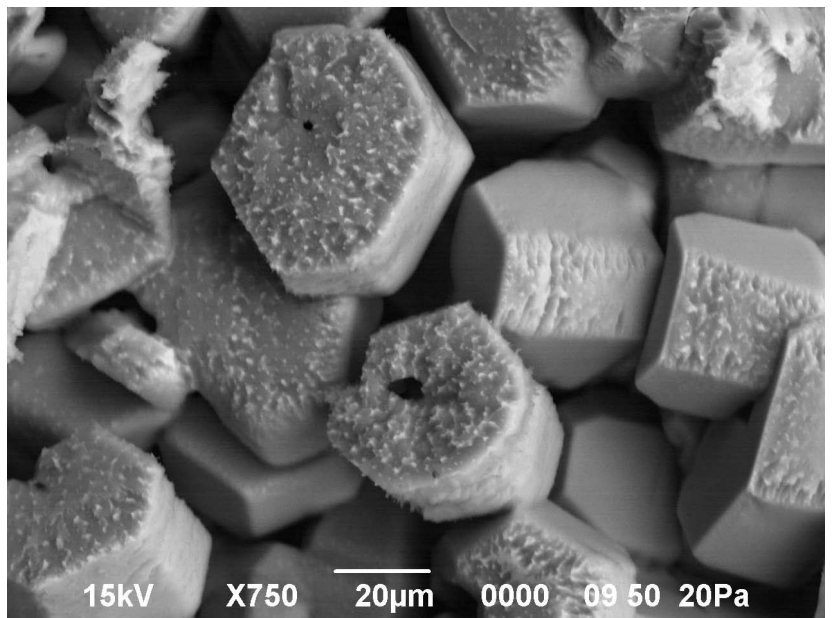

Fig. 10. SEM image of ice crystals sublimating at a temperature of $-30{ }^{\circ} \mathrm{C}$.

et al., 1999). Indeed, high-resolution modelling predicts that ice particle trajectories in mixed-phase clouds contain multiple super- and subsaturated regions (Flossmann and Wobrock, 2010). Thus one of the causes of the ice particle roughness observed in situ may be the cyclic nature of the growth process, at least in the case of mixed-phase clouds. Furthermore, the same modelling shows that a broad range of humidity values can be present, departing widely from equilibrium. In situ cirrus measurements too show a wide variation of humidity, up to the homogeneous freezing threshold and sometimes slightly above (Krämer et al., 2009). Preliminary results from experiments in a flow diffusion chamber, where ice crystals were grown on glass fibres and observed using a laboratory version of SID-3, also indicate increase in roughness following repeated growth cycles (Voigtländer et al., 2013).

We observed substantial roughness on ice particles sublimating on a cold stage of an SEM (Fig. 10), in agreement with other work (Cross, 1969; Pfalzgraff et al., 2010; Neshyba et al., 2013). The emergence of grooves on sublimating prismatic faces may be due to the presence of stacking faults (Kobayashi and Ohtake, 1974; Kuhs et al., 2012). Roughening was also seen when ice analogue crystals were dissolved rapidly (Fig. 12), with roughness superimposed on the overall ellipsoidal shape. These findings are in contrast to the prevailing view that sublimation leads merely to crystal rounding (Nelson, 1998). Despite the somewhat larger scale of ice analogue roughening in comparison to the real ice samples, the analogues appeared more or less rounded in lowerresolution optical microscopy images, adding to the evidence that in situ cloud particle observations using imaging probes (which are characterized by even lower resolution) do not reveal relevant surface detail due to resolution limitations. It is also significant that smooth ice surfaces were visible on SEM images of the same samples where the crystals were partially

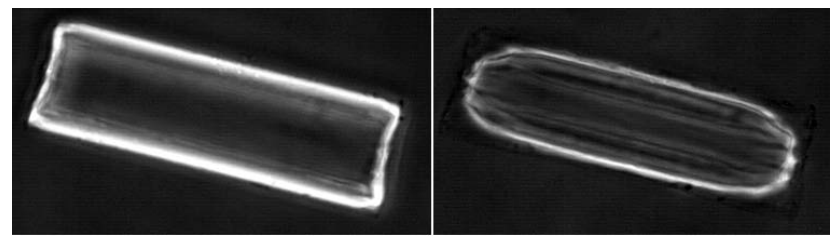

Fig. 11. Optical microscopy images of an ice analogue crystal in subsaturated sodium fluorosilicate solution at the start of dissolving (left) and after approximately $20 \mathrm{~min}$ (right). Initial crystal dimensions were 120 by $37 \mu \mathrm{m}$. Phase contrast was used and contrast stretching applied to emphasize the small difference in the refractive index of the solution (1.33) and the crystal (1.31). The numerical aperture of the objective was 0.4 .

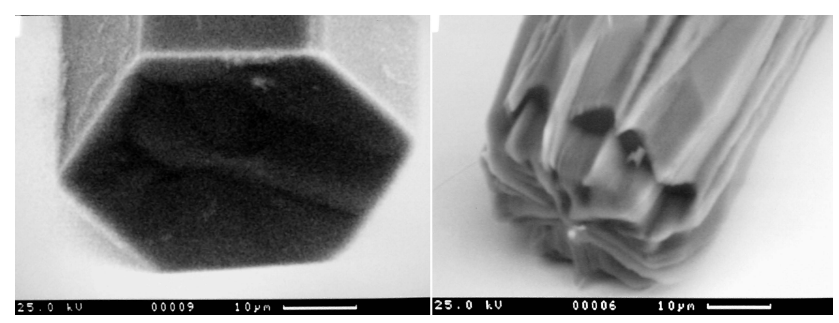

Fig. 12. SEM images of an ice analogue crystal from the same batch as in Fig. 11, before (left) and after approximately $11 \mathrm{~min}$ of dissolving (right). Initial crystal diameter was $50 \mu \mathrm{m}$.

shielded and, hence, were subjected to less severe subsaturation because of lower temperature and/or higher local water vapour pressure (Fig. 10). This suggests that roughness may emerge during sublimation only if ice crystals fall through relatively dry air. On the other hand, if stacking faults were present, localized sublimation might even occur at vapour pressures corresponding to supersaturation with respect to hexagonal ice, as cubic ice has higher vapour pressure than hexagonal ice (Shilling et al., 2006). Roughening during sublimation could explain the apparent roughness of ice particles we found in the sublimation zone of cirrus, even at low humidities (Fig. 8). However, an alternative explanation is that the observed apparent roughness is in part due to increased ice particle complexity caused by high aggregation rates in the sublimation zone (Sölch and Kärcher, 2011).

The lack of correlation between ice supersaturation and roughness, found during the cirrus flights in this study, may be because the presence of roughness is connected to the history of supersaturation stretching over the whole crystal growth period, rather than the instantaneous value during the measurement. Similarly, no correlation is reported between the instantaneous supersaturation and the halo ratio (an indication of crystal "imperfection") determined from the polar nephelometer measurements (Gayet et al., 2011).

It is interesting to observe that, while rough particles dominated in all three cloud types, and marine cirrus and mixedphase clouds were quite similar, cirrus in a continental, polluted airflow showed significantly lower roughness for all 
measures apart from kurtosis. We speculate that this was due to higher concentration of inhomogeneous ice nuclei (IN) in the last case (unfortunately, comparative aerosol measurements were not available for these cases during CONSTRAIN).

It is relevant in this context that high-resolution modelling indicates higher in-cloud ice supersaturation at low IN concentrations in mixed-phase (Flossmann and Wobrock, 2010) and cirrus clouds (Spichtinger and Gierens, 2009). Higher supersaturations would lead to faster crystal growth, which may in turn lead to higher incidence of structural defects, and hence increased roughness. Low supersaturations are known to favour regular crystal growth, with solid, hexagonal prisms at the lower end of the superasaturation scale; conversely, shapes such as "polycrystals" or highly complex dendrites are common at the upper one (Peterson et al., 2010; Bailey and Hallett, 2009, 2004). Incidentally, we found that this was also true of the ice analogues: slow growth, for example due to very slow evaporation of the saturated growth solution, produced regular, solid, prismatic crystals, while rapid evaporation led to dendrites. On the other hand, lower IN concentrations can also increase the contribution from homogeneous nucleation (e.g. Spichtinger and Gierens, 2009), which could potentially influence crystal morphology, as the starting point for growth would be a frozen droplet, so the resulting crystal could become more complex - perhaps of the irregular or the germ rosette type. Such crystals would also produce strong speckle in the 2-D scattering patterns. Whatever the cause, we can term this conjecture the "aerosol hypothesis of roughness".

Cloud chamber experiments focused on inhomogeneous nucleation tend to produce ice crystals with 2-D scattering features indicative of regular geometry and smooth surfaces (Ulanowski et al., 2007; Kaye et al., 2008), probably as a result of relatively low supersaturations present during such experiments. However, there is accumulating evidence from more recent, dedicated experiments in the AIDA cloud chamber that increasing the maximum supersaturation achieved during chamber expansions leads to increased roughness, and that homogeneous nucleation leads to crystals with strongly rough surfaces, as indicated by SID-3 measurements (M. Schnaiter, personal communication, 2013). It is conceivable, therefore, that the excess of rough crystals observed in the clean air mass cirrus flights was due to higher occurrence of homogeneous nucleation. The increased roughness could be a consequence of high incidence of stacking faults in ice crystals, or increased complexity, as already discussed.

The lowering of the shortwave asymmetry parameter required by the inclusion of strong roughness may improve the agreement between global model predictions of cloud brightness. For example, the brightness predicted by some models for the Southern Ocean region, where cirrus incidence is high, is too low (Baran, 2012). Since the air mass over the Southern Ocean is relatively clean, this region would become brighter if strong roughness was included, accordingly to the aerosol hypothesis. However, we note that other factors may also contribute to the discrepancy.

It has been proposed that climate could be modified through aerosol seeding to reduce cirrus cover and optical depth (Mitchell et al., 2011). That such a strategy may be ineffective or even counterproductive is shown by the apparent decrease in roughness with IN concentration and the consequent increase in the asymmetry parameter seen in the present study, as it would result in decreased shortwave reflectivity of the modified cirrus.

\section{Conclusions}

The SID-3 probe was flown on the FAAM BaE-146 aircraft in mid-latitude clouds. Unlike most earlier results from cloud chambers, where SID-3 2-D scattering patterns typically displayed characteristics attributable to idealized geometric crystal shapes, the majority of the cloud patterns showed random, "speckled" appearance. Lab experiments show that such appearance is typical of particles with rough surfaces or complex structure. Quantitative comparison of lab and cloud data was done using pattern texture measures, originally developed for surface roughness analysis using laser speckle. The results are consistent with the presence of strong roughness in the majority of cirrus and mixed-phase cloud ice crystals, at levels similar to those found in rough ice analogue and mineral dust particles used for reference, but some in situ roughness values were higher than for the "roughest" test particles we could obtain. Similar roughness was found in the growth and sublimation zones of cirrus, suggesting that roughness was maintained or possibly even reinforced by sublimation. Slightly weaker roughness was present in cirrus in a polluted air mass of continental origin than in marine cirrus, possibly as an indirect outcome of higher IN concentrations in the former - "the aerosol hypothesis of roughness". The roughness was anticorrelated with the halo ratio determined for single particles.

Finally, in terms of purely technical issues, our analysis was made difficult by the use of lossy JPEG images with very limited, 8-bit dynamic range. This necessitated the use of variable image intensifier gain to allow capturing data from small as well as larger particles. These facts complicated the data analysis and interpretation, and required the rejection of a significant proportion of the data, since all the measures of roughness we used were found to be sensitive to a greater or lesser extent to image brightness, noise, compression artefacts and saturation. SID-3 data from subsequent flying campaigns have been collected as lossless 12-bit TIFF files, without gain switching. These campaigns also provide more accurate and extensive supplementary measurements, such as water vapour concentration for deriving supersaturation, and also aerosol measurement. Among others, this will allow more detailed study of the relationships between ice 
roughness and humidity or IN concentration than was possible in this first, exploratory investigation. The analysis of the new data is already ongoing and will be reported in the near future. We have also initiated experimental and theoretical studies to determine the single-scattering properties, including the asymmetry parameter, of particles with geometries corresponding to those that dominated the in situ measurements in the present study, so that the impact of our findings on the radiative properties of cirrus and mixed-phase clouds can be quantified.

Acknowledgements. This work was supported by the UK Natural Environment Research Council grants NE/E011225/1 (APPRAISE) and NE/I020067/1 (ACID-PRUF). We are indebted to Robert Williamson for skilful assistance in carrying out the ice analogue dissolving experiments and to Ken Henman for the electron microscopy of ice. We are grateful to the Facility for Airborne Atmospheric Measurements (FAAM) team for making possible the measurements reported here and for providing excellent support throughout the CONSTRAIN campaign. We also gratefully acknowledge the NOAA Air Resources Laboratory for the provision of the HYSPLIT transport model.

Edited by: T. Garrett

\section{References}

Auriol, F., Gayet, J.-F., Febvre, G., Jourdan, O., Labonnote, L., and Brogniez, G.: In situ observations of cirrus cloud scattering phase function with $22^{\circ}$ and $46^{\circ}$ halos: cloud field study on 19 February 1998, J. Atmos. Sci., 58, 3376-3390, 2001.

Bailey, M. and Hallett, J.: Growth rates and habits of ice crystals between -20 and $-70^{\circ} \mathrm{C}$, J. Atmos. Sci., 61, 514-544, 2004.

Bailey, M. P. and Hallett, J. A.: Comprehensive habit diagram for atmospheric ice crystals: confirmation from the laboratory, AIRS II, and other field studies, J. Atmos. Sci., 66, 2888-2899, 2009.

Baran, A. J.: On the scattering and absorption properties of cirrus cloud, J. Quant. Spectrosc. Ra., 89, 17-36, 2004.

Baran, A. J.: From the single-scattering properties of ice crystals to climate prediction: a way forward, Atmos. Res., 112, 45-69, 2012.

Baran, A. J., Francis, P. N., Labonnote, L.-C., and DoutriauxBoucher, M.: A scattering phase function for ice cloud: tests of applicability using aircraft and satellite multi-angle multiwavelength radiance measurements of cirrus, Q. J. Roy. Meteor. Soc., 127, 2395-2416, 2001.

Baum, B. A., Yang, P., Heymsfield, A. J., Schmitt, C. G., Xie, Y., Bansemer, A., Hu, Y.-X., and Zhang, Z.: Improvements in shortwave bulk scattering and absorption models for the remote sensing of ice clouds, J. Appl. Meterol. Clim., 50, 1037-1056, 2011.

Clarke, A. J. M., Hesse, E., Ulanowski, Z., and Kaye, P. H.: A 3$\mathrm{D}$ implementation of ray tracing combined with diffraction on facets, J. Quant. Spectrosc. Ra., 100, 103-114, 2006.

Cole, B. H., Yang, P., Baum, B. A., Riedi, J., Labonnote, L. C., Thieuleux, F., and Platnick, S.: Comparison of PARASOL observations with polarized reflectances simulated using different ice habit mixtures, J. Appl. Meterol. Clim., 52, 186-196, 2013.
Connolly, P. J., Flynn, M. J., Ulanowski, Z., Choularton, T. W., Gallagher, M. W., and Bower, K. N.: Calibration of 2-D imaging probes using calibration beads and ice crystal analogues, J. Atmos. Ocean. Tech., 24, 1860-1879, 2007.

Cotton, R., Osborne, S., Ulanowski, Z., Hirst, E., Kaye, P. H., and Greenaway, R.: The ability of the Small Ice Detector, SID2 to characterise cloud particle and aerosol morphologies obtained during flights of the FAAM BAe-146 research aircraft, J. Atmos. Ocean. Tech., 27, 290-303, 2010.

Cotton, R. J., Field, P. R., Ulanowski, Z., Kaye, P. H., Hirst, E., Greenaway, R. S., Crawford, I., Crosier, J., and Dorsey, J.: The effective density of small ice particles obtained from in situ aircraft observations of mid-latitude cirrus, Q. J. Royal Meteor. Soc., 139, 1923-1934, 2013.

Cross, J. D.: Scanning electron microscopy of evaporating ice, Science, 164, 174-175, 1969.

Draxler, R. R. and Rolph, G. D.: HYSPLIT (HYbrid SingleParticle Lagrangian Integrated Trajectory) model access via NOAA ARL READY Website, available at: http://www.arl.noaa. gov/HYSPLIT.php (last access: 29 August 2013), NOAA Air Resources Laboratory, Silver Spring, 2003.

Fahey, D. W., Gao, R. S., and Möhler, O.: Summary of the AquaVIT Water Vapor Intercomparison: Static Experiments, AquaVIT White Paper, Institute for Meteorology and Climate Research, Karlsruhe, available at: https://aquavit.icg.kfa-juelich.de/ WhitePaper/AquaVITWhitePaper_Final_23Oct2009_6MB.pdf (last access: 22 August 2013), 2009.

Field, P. R., Baran, A. J., Kaye, P. H., Hirst, E., and Greenaway, R.: a test of cirrus ice crystal scattering phase functions, Geophys. Res. Lett., 30, 1752, doi:10.1029/2003GL017482, 2003.

Field, P. R., Heymsfield, A. J., and Bansemer, A.: Shattering and particle interarrival times measured by optical array probes in ice clouds, J. Atmos. Ocean. Tech., 23, 1357-1371, 2006.

Flossmann, A. I. and Wobrock, W.: A review of our understanding of the aerosol-cloud interaction from the perspective of a bin resolved cloud scale modeling, Atmos. Res., 97, 478-497, 2010.

Foot, J. S.: Some observations of the optical properties of clouds. II: Cirrus, Q. J. Roy. Meteor. Soc., 114, 145-164, 1988.

Garrett, T. J.: Observational quantification of the optical properties of cirrus cloud, in: Light Scattering Reviews 3, Springer, Berlin, 3-26, 2008.

Garrett, T. J., Hobbs, P. V., and Gerber, H.: Shortwave, singlescattering properties of arctic ice clouds, J. Geophys. Res., 106, 15155-15172, doi:10.1029/2000JD900195, 2001.

Gayet, J.-F., Mioche, G., Shcherbakov, V., Gourbeyre, C., Busen, R., and Minikin, A.: Optical properties of pristine ice crystals in mid-latitude cirrus clouds: a case study during CIRCLE-2 experiment, Atmos. Chem. Phys., 11, 2537-2544, doi:10.5194/acp-11-2537-2011, 2011.

Goodman, J. W.: Speckle Phenomena in Optics: Theory and Applications, Roberts, Englewood, 2007.

Guignard, A., Stubenrauch, C. J., Baran, A. J., and Armante, R.: Bulk microphysical properties of semi-transparent cirrus from AIRS: a six year global climatology and statistical analysis in synergy with geometrical profiling data from CloudSatCALIPSO, Atmos. Chem. Phys., 12, 503-525, doi:10.5194/acp12-503-2012, 2012. 
Haralick, R. M., Shanmugam, K., and Dinstein, I.: Texture features for image classification, IEEE T. Syst. Man Cyb., 3, 610-621, 1973.

Hesse, E., McCall, D. S., Ulanowski, Z., Stopford, C., and Kaye, P. H.: Application of RTDF to particles with curved surfaces, J. Quant. Spectrosc. Ra., 110, 1599-1603, 2009.

Hesse, E., Macke, A., Havemann, S., Baran, A. J., Ulanowski, Z., and Kaye, P. H.: Modelling diffraction by facetted particles, J. Quant. Spectrosc. Ra., 113, 342-347, 2012.

Jolic, K. I., Nagarajah, C. R., and Thompson, W.: Non-contact, optically based measurement of surface roughness of ceramics, Meas. Sci. Technol., 5, 671-684, 1994.

Jourdan, O., Mioche, G., Garrett, T. J., Schwarzenböck, A., Vidot, J., Xie, Y., Shcherbakov, V., Yang, P., and Gayet, J. F.: Coupling of the microphysical and optical properties of an Arctic nimbostratus cloud during the ASTAR 2004 experiment: Implications for light-scattering modeling, J. Geophys. Res., 115, D23206, doi:10.1029/2010JD014016, 2010.

Kaye, P. H., Hirst, E., Greenaway, R. S., Ulanowski, Z., Hesse, E., DeMott, P., Saunders, C., and Connolly, P.: Classifying atmospheric ice crystals by spatial light scattering, Opt. Lett., 33, 1545-1547, 2008.

Keramitsoglou, I., Harries, J. E., Colling, D. J., Barker, R. A., and Foot, J. S.: A study of the theory and operation of a resonance fluorescence water vapour sensor for upper tropospheric humidity measurements, Meteorol. Appl., 9, 443-453, 2002.

Kobayashi, T. and Ohtake, T.: Hexagonal twin prisms of ice, J. Atmos. Sci., 31, 1377-1383, 1974.

Korolev, A. V., Isaac, G. A., and Hallett, J.: Ice particle habits in Arctic clouds, Geophys. Res. Lett., 26, 1299-1302, 1999.

Korolev, A., Isaac, G. A., and Hallett, J.: Ice particle habits in stratiform clouds, Q. J. Roy. Meteor. Soc., 126, 2873-2902, 2000.

Krämer, M., Schiller, C., Afchine, A., Bauer, R., Gensch, I., Mangold, A., Schlicht, S., Spelten, N., Sitnikov, N., Borrmann, S., de Reus, M., and Spichtinger, P.: Ice supersaturations and cirrus cloud crystal numbers, Atmos. Chem. Phys., 9, 3505-3522, doi:10.5194/acp-9-3505-2009, 2009.

Kuhs, W. F., Sippel, C., Falenty, A., and Hansen, T. C.: Extent and relevance of stacking disorder in "ice Ic", P. Natl. Acad. Sci. USA, 109, 21259-21264, 2012.

Lampert, A., Ehrlich, A., Dörnbrack, A., Jourdan, O., Gayet, J.F., Mioche, G., Shcherbakov, V., Ritter, C., and Wendisch, M.: Microphysical and radiative characterization of a subvisible midlevel Arctic ice cloud by airborne observations - a case study, Atmos. Chem. Phys., 9, 2647-2661, doi:10.5194/acp-9-26472009, 2009.

Lu, R. S., Tian, G. Y., Gledhill, D., and Ward, S.: Grinding surface roughness measurement based on the co-occurrence matrix of speckle pattern texture, Appl. Optics, 45, 8839-8847, 2006.

Malkin, T. L., Murray, B. J., Brukhno, A. V., Anwar, J., and Salzmann, C. G.: The structure of ice crystallised from supercooled water, P. Natl. Acad. Sci. USA, 109, 1041-1045, 2012.

McCall, D. S.: Measurement and modelling of light scattering by small to medium size parameter airborne particles, Ph.D. thesis, University of Hertfordshire, Hatfield, 2011.

Mishchenko, M. I. and Macke, A.: Incorporation of physical optics effect and computation of the Legendre expansion for ray-tracing phase functions involving d-function transmission, J. Geophys. Res., 103, 1799-1805, 1998.
Mishchenko, M. I. and Macke, A.: How big should hexagonal ice crystals be to produce halos?, Appl. Optics, 38, 1626-1629, 1999.

Mitchell, D. L., Mishra, S., and Lawson, R. P.: Cirrus clouds and climate engineering: new findings on ice nucleation and theoretical basis, in: Planet Earth 2011, edited by: Carayannis, E., InTech, Rijeka, 257-288, 2011.

Nelson, J.: Sublimation of ice crystals, J. Atmos. Sci., 55, 910-919, 1998.

Neshyba, S. P., Lowen, B., Benning, M., Lawson, A., and Rowe, P. M.: Roughness metrics of prismatic facets of ice, J. Geophys. Res., 118, 3309-3318, 2013.

Nousiainen, T., Lindqvist, H., McFarquhar, G. M., and Um, J.: Small irregular ice crystals in tropical cirrus, J. Atmos. Sci., 68, 2614-2627, 2011.

Peterson, H., Bailey, M., and Hallett, J.: Ice particle growth under conditions of the upper troposphere, Atmos. Res., 97, 446-449, 2010.

Pfalzgraff, W. C., Hulscher, R. M., and Neshyba, S. P.: Scanning electron microscopy and molecular dynamics of surfaces of growing and ablating hexagonal ice crystals, Atmos. Chem. Phys., 10, 2927-2935, doi:10.5194/acp-10-2927-2010, 2010.

Ruiz Gale, M. F., Hogert, E. N., and Gaggioli, N. G.: Apparent and real roughness, Opt. Laser. Eng., 45, 947-952, 2007.

Schön, R., Schnaiter, M., Ulanowski, Z., Benz, S., Möhler, O., Vogt, S., Wagner, R., and Schurath, U.: Particle habit imaging using incoherent light: a first step towards a novel instrument for cloud microphysics, J. Atmos. Ocean. Tech., 28, 493-512, 2011.

Shcherbakov, V.: Why the $46^{\circ}$ halo is seen far less often than the $22^{\circ}$ halo?, J. Quant. Spectrosc. Ra., 124, 37-44, 2013.

Shcherbakov, V., Gayet, J. F., Jourdan, O., Ström, J., and Minikin, A: Light scattering by single ice crystals of cirrus clouds, Geophys. Res. Lett., 33, L15809, doi:10.1029/2006GL026055, 2006.

Shilling, J. E., Tolbert, M. A., Toon, O. B., Jensen, E. J., Murray, B. J., and Bertram, A. K.: Measurements of the vapor pressure of cubic ice and their implications for atmospheric ice clouds, Geophys. Res. Lett., 33, L17801, doi:10.1029/2006GL026671, 2006.

Sölch, I. and Kärcher, B.: Process-oriented large-eddy simulations of a midlatitude cirrus cloud system based on observations, Q. J. Roy. Meteor. Soc., 137, 374-393, 2011.

Spichtinger, P. and Gierens, K. M.: Modelling of cirrus clouds - Part 2: Competition of different nucleation mechanisms, Atmos. Chem. Phys., 9, 2319-2334, doi:10.5194/acp-9-2319-2009, 2009.

Takano, Y. and Liou, K. N.: Solar radiative transfer in cirrus clouds. I. Single-scattering and optical properties of hexagonal ice crystals, J. Atmos. Sci., 46, 3-19, 1989.

Ulanowski, Z.: Ice analog halos, Appl. Optics, 44, 5754-5758, 2005.

Ulanowski, Z., Hesse, E., Kaye, P. H., Baran, A. J., and Chandrasekhar, R.: Scattering of light from atmospheric ice analogues, J. Quant. Spectrosc. Ra., 79-80C, 1091-1102, 2003.

Ulanowski, Z., Connolly, P., Flynn, M., Gallagher, M., Clarke, A. J. M., and Hesse, E.: Using ice crystal analogues to validate cloud ice parameter retrievals from the CPI ice spectrometer, in: Proc. 14 Int. Conf. Clouds Precip., Bologna, 19-23 July 2004, 1175-1178, available at: 
uhra.herts.ac.uk/handle/2299/6753 (last access: 17 September 2013), 2004.

Ulanowski, Z., Hesse, E., Kaye, P. H., and Baran, A. J.: Light scattering by complex ice-analogue crystals, J. Quant. Spectrosc. Ra., 100, 382-392, 2006.

Ulanowski, Z., Stopford, C., Hesse, E., Kaye, P. H., Hirst, E., and Schnaiter, M.: Characterization of small ice crystals using frequency analysis of azimuthal scattering patterns, in: Proc. 10 Int. Conf. on Electromagnetic and Light Scattering, Bodrum, 17-23 June, 225-228, 2007.

Ulanowski, Z., Hirst, E., Kaye, P. H., and Greenaway, R.: Retrieving the size of particles with rough and complex surfaces from twodimensional scattering patterns, J. Quant. Spectrosc. Ra., 113, 2457-2464, 2012.

Um, J. and McFarquhar, G. M.: Dependence of the single-scattering properties of small ice crystals on idealized shape models, Atmos. Chem. Phys., 11, 3159-3171, doi:10.5194/acp-11-31592011, 2011.
Voigtländer, J., Bieligk, H., Niedermeier, D., Clauss, T., Chou, C., Ulanowski, Z., and Stratmann, F.: A new experimental setup to investigate nucleation, dynamic growth and surface properties of single ice crystals, in: Geophys. Res. Abs., 15, EGU General Assembly, Vienna, Austria, EGU2013-4206, 2013.

Yang, P. and Liou, K. N.: Single-scattering properties of complex ice crystals in terrestrial atmosphere, Contr. Atmos. Phys., 71, 223-248, 1998.

Yang, P., Zhang, Z., Kattawar, G. W., Warren, S. G., Baum, B. A., Huang, H. L., Hu, Y. X., Winker, D., and Iaquinta, J.: Effect of cavities on the optical properties of bullet rosettes, Appl. Meteorol. Clim., 47, 2311-2330, 2008. 